\title{
Lumbar Disc Herniation with End-Plate Fracture and Secondary Ossification Mimicking an Epidural Tumor: A Case Report
}

\author{
Koun Yamauchi $^{1}$, Akira Hioki ${ }^{2}$, Kazunari Fushimi ${ }^{3}$, Kei Miyamoto ${ }^{4}$, Katsuji Shimizu ${ }^{2}$ \\ ${ }^{1}$ Department of Orthopaedic Surgery, Hikone Municipal Hospital, Shiga, Japan; ${ }^{2}$ Department of Orthopaedic Surgery, Gifu Univer- \\ sity School of Medicine, Gifu, Japan; ${ }^{3}$ Department of Orthopaedic Surgery, Kizawa Memorial Hosptial, Gifu, Japan; ${ }^{4}$ Department of \\ Reconstructive Surgery for Spine, Bone, and Joint, Gifu University School of Medicine, Gifu, Japan. \\ Email: koun_yamauchi@yahoo.co.jp; akira-hi@amber.plala.or.jp; kfus@gifu-u.ac.jp; kei@bg8.so-net.ne.jp; shim@gifu-u.ac.jp
}

Received March $11^{\text {th }}, 2013$; revised April 30 ${ }^{\text {th }}, 2013$; accepted May $14^{\text {th }}, 2013$

Copyright (c) 2013 Koun Yamauchi et al. This is an open access article distributed under the Creative Commons Attribution License, which permits unrestricted use, distribution, and reproduction in any medium, provided the original work is properly cited.

\begin{abstract}
We report a unique case of lumbar disc herniation, in particular, with end-plate and surrounded by extensive ossification, mimicking a tumor with calcification. A 69-year-old female suffered from right buttock and leg pain. Computed tomography (CT) showed an intracanalar mass with calcification or ossification, which most likely originated from the vertebral body at the L1/2 level epidural space. On a T1-weighted gadolinium magnetic resonance image, the capsule of the mass was enhanced and not only the content of the mass but also that of the L2 vertebral body were partially and slightly enhanced. The final pathological diagnosis was disc herniation with end-plate fracture and secondary ossification. A combination of these pathological conditions as accompanied by both end-plate fractures and extensive secondary ossifications has not been previously reported. This rare pathological condition needs to be recognized as a differential diagnosis.
\end{abstract}

Keywords: Disc Herniation; Extensive Ossifications; End-Plate Fractures

\section{Introduction}

It has been suggested that a lumbar disc herniation with "bony fragments" or "calcifications" mimics an epidural tumor [1-5]. On the other hand, it has also been reported that not only a benign tumor; extraosseous [6], chondroma [7], but also malignant tumor; granular cell tumor [8], capillary hemangioma [9] mimics a vertebra disc herniation. Therefore, this pathological condition is difficult to diagnose on the basis of physical and radiological information only.

We report a rare case of lumbar disc herniation, pathologically, with a bony fragment from the end-plate in which diagnosis was difficult because it was accompanied by the ossification.

The purpose of this report is to document the pathological condition, which mimics an epidural tumor, needs to be recognized as a differential diagnosis.

\section{Case Presentation}

A 69-year-old female had suffered from lower back, right buttock, and posterior thigh pain for nearly 30 years. Her symptoms worsened 1 year back and she visited our outpatient clinic. On physical examination, no neurological abnormalities, including muscle weakness and bladder function disorder, were recognized, except for severe pain in her lower back, right buttock, and right posterior thigh.

Plain AP and lateral radiographs of the lumbar spine showed a high density area at the posteroinferior L1 and posterosuperior L2 walls; in addition, an intervertebral degenerative change at L1/2 and osteoporosis were observed. Computed tomography (CT) showed an epidural calcified or ossified mass at L1/2 and bony sclerosis of the posterior L2 vertebra (Figures 1(a) and (b)). CT myelography showed the mass lesion compressing the dual sac posterocentrally to the right side. Magnetic resonance imaging (MRI) showed the presence of a hypointense lesion on T1-weighted images and a partly hyperintense and partly hypointense lesion on T2-weighted images (Figures 2(a) and (b)). Gadolinium-enhanced contrast images showed partial enhancement of the capsule, paren- 


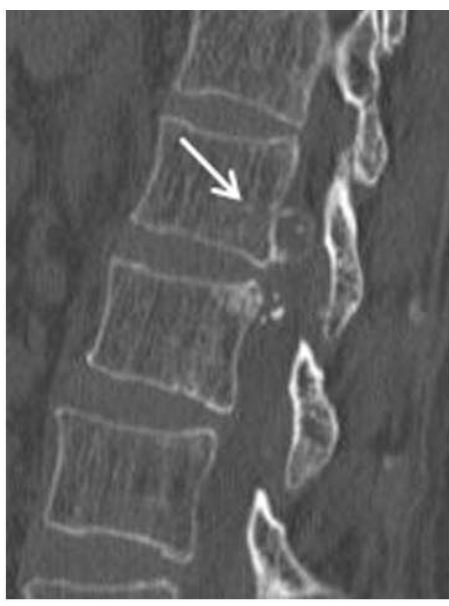

(a)

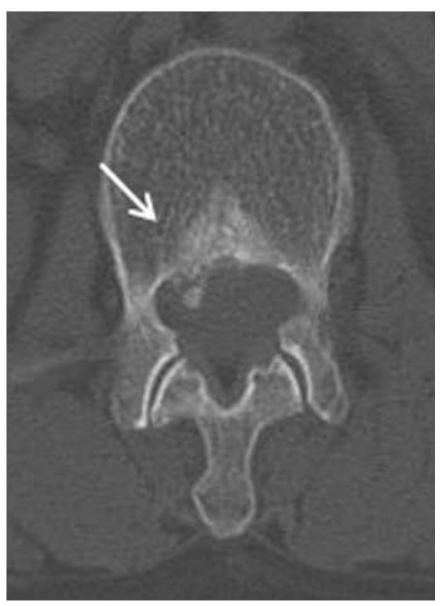

(b)

Figure 1. Computed tomography scan: A sagittal image (a) demonstrates the mass as a high-density area (arrow) located centrally to the right at the level of the $L 1$ and $L 2$ lumbar canal. An axial image (b) of $L 2$ demonstrates the mass as a high-density area with sclerosis of the $\mathrm{L} 2$ body (arrow).

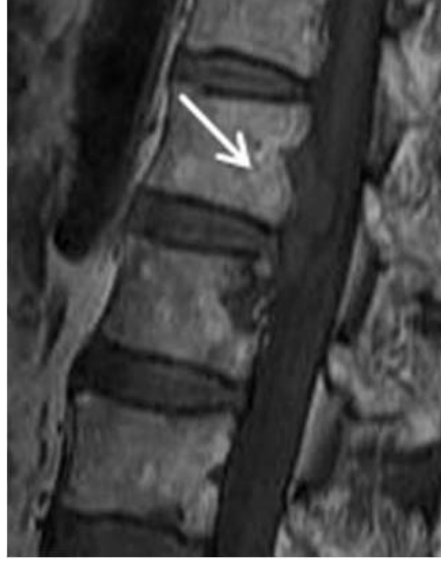

(a)

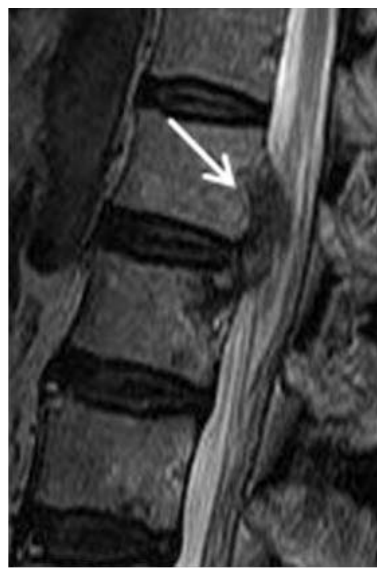

(b)

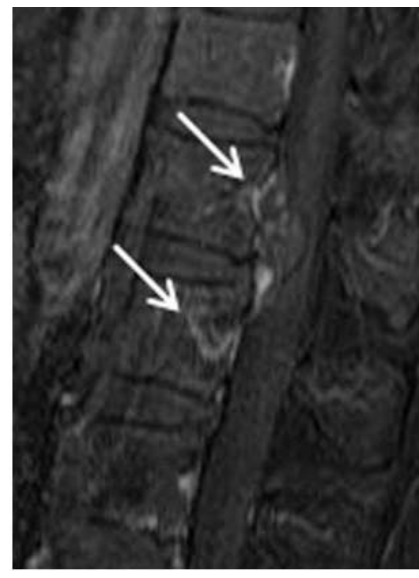

(c)

Figure 2. Magnetic resonance images: A T1: weighted image (a) shows the presence of a hypointense lesion. A T2: weighted image (b) shows a partly hyperintense and partly hypointense lesion. A gadolinium-enhanced contrast image (c) shows partial enhancement of the capsule, parenchyma, and L2 vertebra (arrows).

chyma, and L2 vertebra (Figure 2(c)).Thallium scintigraphy did not demonstrate any accumulation in the mass.

Preoperatively, we did not consider the mass to be malignant, but more likely to be disc herniation or an epidural tumor, including meningioma or osteochondroma. We planned to carry out total resection of the mass and decompression of the conusmedullaris via right-sidedfacetectomy of L1/2 and transforaminal lumbar interbody fusion (TLIF) followed by postoperative therapy with a frame corset, because dual-energy X-ray absorptiometry (DEXA) of the radius bone showed osteoporosis.

\section{Operative Findings}

The elastichard and flexible subligamentous mass was observed after facetectomy. A rapid pathological evalua- tion of the mass during surgery resulted in a diagnosis of degenerative herniation. Therefore, we first removed a part of the extruded herniated disc piece by piece for histopathological examination. Then, we found that the periosteum of the posteroinferior wall of L1 and the posterosuperior wall of L2 was already peeled and could be removed easily. Next, we completely removed the disc at L1/2 and performed interbody fusion by posterior instrumentation (Figures 3(a) and (b)).

Postoperative CT showed complete resection of the herniated disc and decompression of the dural sac. Preoperative symptoms (buttock and leg pain) completely disappeared after the operation. From the histopathological point of view, three observations were noted: 1) most of the tissue was diagnosed as degenerated annulus, 2) some end-plates had an annulus (Figures 4(a) and (b)), 


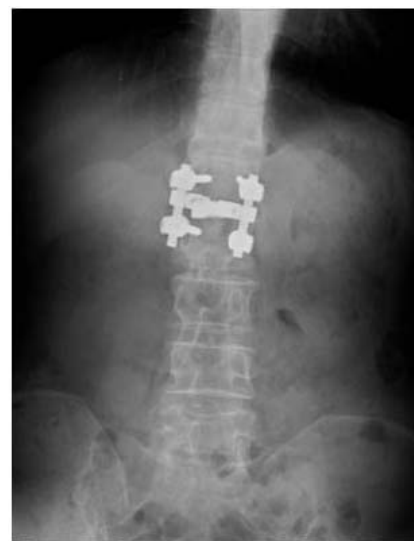

(a)

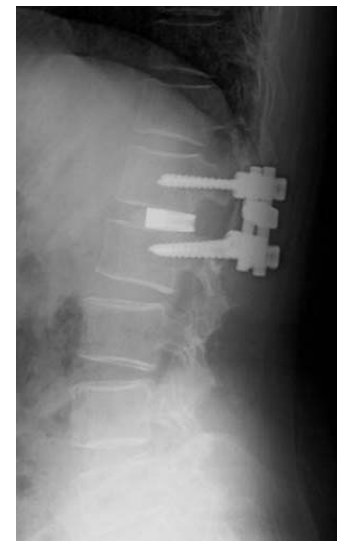

(b)
Figure 3. Postoperative anteroposterior (a) and lateral (b) plain X-ray images of transforaminal lumbar interbody fusion (TLIF) between L1 and L2.

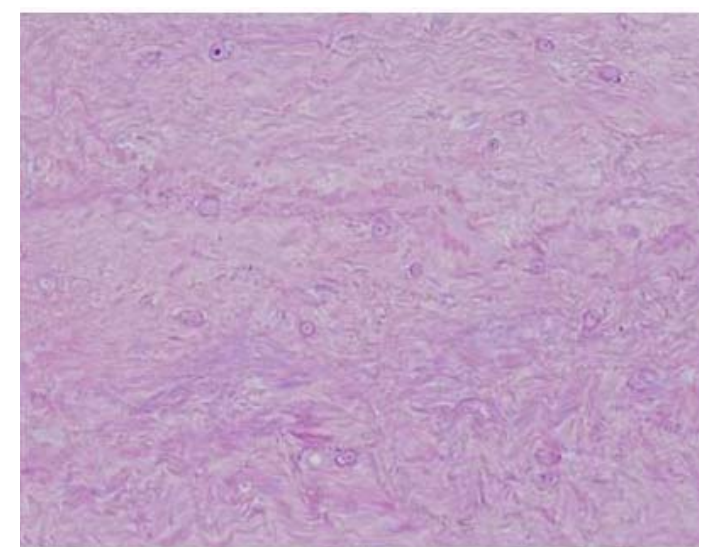

(a)

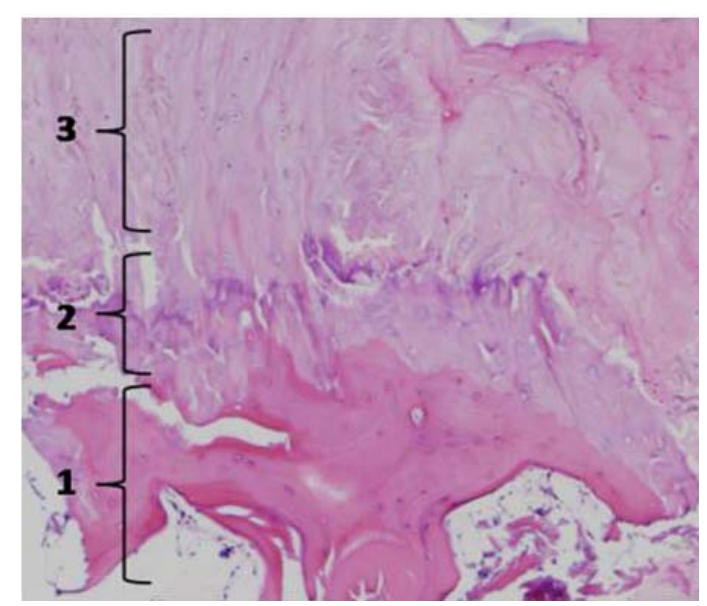

(b)

Figure 4. Histopathological images: Histopathological observation of the surgical specimen revealed it to be a degenerative intervertebral disc (a) and an end-plate (b), which displayed a consecutive layer structure (1: bone layer, 2: cartilage plate layer with hyaline cartilage, 3 : annulus fibrosus). and 3) secondary ossification was identified around the end-plate.

\section{Discussion}

In this case, the pathogenesis of the herniated disc at the L1/2 level was extremely rare because it was accompanied not only by end-plate fractures, but also by extensive secondary ossifications along the peeled periosteum of the vertebral body. A combination of these pathological conditions, which mimic an extradural tumor, has not been previously reported.

In fact, herniated discs with end-plate fractures have been observed in young patients and have been recognized as juvenile herniated discs with marginal cartilaginous nodes or posterior ring apophysis separation (PRAS). Akhaddar et al. reported that PRAS had the following characteristics: 1) a high incidence in adolescents and young males and 2) no relationship to previous trauma but some relationship to chronic stress in cases with prolonged duration of symptoms [10]. Therefore, from the viewpoints of histopathology and age, the disc herniation with end-plate fracture seen in the present case cannot be characterized as PRAS.

A possible pathomechanism in our case is as follows. First, the bone quality of the vertebral body was osteoporotic, as was seen on DEXA of the radius bone. Second, the translational force of a daily activity was continuously loaded onto the intervertebral space and onto the posteroinferior edge of the vertebral body. Third, the posterior part of the annulus fibrosus was herniated posteriorly and was accompanied by osteoporotic avulsion fracture of the vertebral end-plates. Finally, it can be hypothesized that secondary ossification developed within the canal along the periosteum that had been peeled from the posteroinferior wall of L1 and the posterosuperior wall of L2. Additionally, as far as we could discern from the CT image of the entire spine in the present case, ossification of the posterior longitudinal ligament (OPLL) was excluded from the differential diagnosis.

This rare pathological condition with lumbar disc herniation accompanying development of a bony fragment from the end-plate and extensive ossification, which mimics an epidural tumor, needs to be recognized and helpful as a differential diagnosis.

\section{REFERENCES}

[1] H. Baba and S. Imura, "An Unusual Ossified Thoracic Disc Herniation,” International Orthopaedics, Vol. 17, No. 5, 1993, pp. 290-292. doi:10.1007/BF00181701

[2] A. Inui, K. Sairyo, S. Katoh, K. Higashino, T. Sakai, M. Shiiba and N. Yasui, "Extruded Lumbar Osseous Endplate Causing Long-Term Radiculopathy in an Adult: An En- 
doscopic Excision,” Minimally Invasive Neurosurgery, Vol. 49, No. 1, 2006, pp. 55-57. doi:10.1055/s-2005-919165

[3] G. L. Ackland, J. O’Beirne, A. R. Platts and S. C. Ward, "False-Positive Presentation of Battle's Sign during Hepatic Encephalopathy,” Neurocritical Care, Vol. 9, No. 2, 2008, pp. 253-252. doi:10.1007/s12028-008-9116-5

[4] J. L. Leroux, J. M. Fuentes, P. Baixas, J. Benezech, P. Chertok and F. Blotman, "Lumbar Posterior Marginal Node (LPMN) in Adults. Report of Fifteen Cases,” Spine, Vol. 17, No. 12, 1992, pp. 1505-1508.

[5] A. B. Lippitt, "Fracture of Vertebral Body End Plate and Disk Protrusion Causing Subarachnoid Block in an Adolescent," Clinical Orthopaedics and Related Research, Vol. 116, 1976, pp. 112-115.

[6] R. D. Guyer, R. R. Collier, D. D. Ohnmeiss, W. J. Stith, S. H. Hochschuler, R. F. Rashbaum, H. Vanharanta and V. Loguidice, "Extraosseous Spinal Lesions Mimicking Disc Disease,” Spine, Vol. 13, No. 3, 1998, 328-331.
[7] S. F. Erten, A. Kocak, B. Mizrak, R. Kutlu and A. Colak, "An End-Plate Chondroma Mimicking Calcified Lumbar Disc Herniation. A Case Report and Review of the Literature,” Neurosurgical Review, Vol. 22, No. 2-3, 1999, pp. 145-148. doi:10.1007/s101430050051

[8] A. L. Saperstein, R. Lusskin, A. E. Doniguian, P. A. Thomas and A. F. Battista, "Malignant Granular Cell Tumor Mimicking Herniated Nucleus Pulposus," Clinical Orthopaedics and Related Research, Vol. 324, 1996, pp. 244250. doi:10.1097/00003086-199603000-00030

[9] T. Tekin, F. Bayrakli, H. Simsek, A. Colak, M. Kutlay and M. N. Demircan, "Lumbar Epidural Capillary Hemangioma Presenting as Lumbar Disc Herniation Disease: Case Report,” Spine, Vol. 33, No. 21, 2008, pp. 795-797.

[10] A. Akhaddar, H. Belfquih, M. Oukabli and M. Boucetta, "Posterior Ring Apophysis Separation Combined with Lumbar Disc Herniation in Adults: A 10-Year Experience in the Surgical Management of 87 Cases," Journal of Neurosurgery: Spine, Vol. 14, No. 4, 2008, pp. 475-483. doi:10.3171/2010.11.SPINE10392 